\title{
ПРИОРИТЕТЫ СОВЕРШЕНСТВОВАНИЯ БЮДЖЕТНОЙ ПОЛИТИКИ В РЕСПУБЛИКЕ КАЗАХСТАН*
}

\author{
Маргарита Кадырова \\ Академия государственного управления \\ при Президенте Республики Казахстан, \\ Астана, Республика Казахстан, ул. Абая 33 «а». \\ doi:10.13165/VPA-13-12-4-07
}

\begin{abstract}
Аннотация. В представленной статье рассмотрены актуальные вопросы формирования и реализации бюджетной политики Республики Казахстан, проводится анализ механизмов совершенствования методов бюджетного планирования, повышения эффективности использования бюджетных ресурсов. Особый акиент сделан на сущзествующих проблемах в бюджетной сфере, что предопределяет необходимость дальнейших исследований в этой области.
\end{abstract}

Ключевые слова: Бюджетнаяполитика, бюджетныйпроиесс, государственное планирование, бюджетное планирование, эффективность бюджетных расходов, управление государственными финансами.

Keywords: Fiscal policy, the budget process, state planning, budget planning, the effectiveness of budget expenditure, public financial management.

\section{Введение}

В настоящее время складываются благоприятные условия для ускорения реформирования и совершенствоания бюджетной политики Казахстана, цель которой - создать предпосылки и обеспечить условия для максимально эффективного использования бюджетных ресурсов в соответствии с приоритетами социально-экономической политики государства. Посланием Президента Рес-

* This article is part of the electronic conference: „Public Administration in Central Europe: In Search of Tradition“ organized by the Institute of Public Administration at Mykolas Romeris University (Vilnius, Lithuania) in partnership with the Academic Association of Management and Administration (Lithuania) on November 6th and 7th, 2013. 
публики Казахстан Стратегия «Казахстан-2050» Новый политический курс состоявшегося государства определено, что «мы должны вооружиться новым принципом бюджетной политики - тратить только в пределах своих возможностей и сократить дефицит до максимально возможного минимума» [1]. Важнейшей составляющей бюджетной политики является система бюджетного планирования, в которой назрела реальная необходимость создания качественно новой системы планирования и мониторинга социально-экономической результативности бюджетных расходов с помощью качественных и количественных индикаторов как в отношении бюджетов всех уровней, так и в отношении конкретных бюджетополучателей. В 2007 году была принята Концепция по внедрению системы государственного планирования, ориентированного на результаты [2] и внесены изменения и дополнения в Бюджетный кодекс [3], что обеспечило правовую основу бюджетной реформы.

Вопросы совершенствования бюджетной политики в Республике Казахстан, механизмов реформирования бюджетного планирования, проблемы повышения эффективности реализации бюджетных программ исследуются в представленной статье.

\section{Теоретические аспекты исследования}

Различные теоретические и прикладные аспекты совершенствования инструментов бюджетной политики, внедрения новых подходов в бюджетном планировании, реформирования межбюджетных отношений, оценки эффективности бюджетных расходов изучались многими зарубежными и казахстанскими учеными.

Большой вклад в теорию бюджетного процесса внесли видные зарубежные ученые. Так, в развитии теории бюджетного регулирования и бюджетной эффективности значительную роль сыграли работы П. Терни [4], Блондала Й. [5], Кристенсена Й. [6], и других. В вопросах повышения эффективности управления интерес представляют труды таких авторов, как Чертана К. [7], Гордона Г. [8], Юнгмана И. [9] и др. Особое место в теории бюджетной политики занимают вопросы реформирования местных бюджетов, совершенствования межбюджетных отношений. Данные вопросы достаточно глубоко были проанализированы в работах таких российских ученых, как А. Г. Силуанов [10], М. В. Васильева [11], казахстанских ученых - А. Б. Зейнельгабдин [12], Н.К. Кучукова [13] и др.

Несмотря на то, что вопросам совершенствования бюджетной политики и эффективного управления бюджетными средствами уделено значительное внимание в зарубежной экономической литературе, следует отметить, что в казахстанской литературе степень разработанности проблемы недостаточна. В отечественных источниках, в основном, описываются лишь общие правила и процедуры формирования и реализации бюджетной политики, а также оценки эффективности использования бюджетных средств, причем основной акцент делается именно на 
контроле деятельности бюджетных учреждений, и упускаются из виду все остальные стадии управления бюджетными средствами - анализ, планирование, организация исполнения, учет, регулирование. Все это предопределяет актуальность рассматриваемых в статье вопросов и поднимаемых проблем.

\section{Особенности реализации бюджетной политики на современном этапе}

Последние десятилетия общество стало предъявлять новые, все более жесткие требования к государству в части качества выполнения им своих функций. Правительство Республики Казахстан в рамках проводимой реформы бюджетной политики, начиная с 2007 года, приступило к внедрению основных принципов и подходов бюджетирования, ориентированного на результаты. Принятый в 2008 году Бюджетный Кодекс впервые на законодательном уровне укрепил внедрение принципов бюджетирования, ориентированного на результат в практику бюджетного планирования [3].

К достоинствам бюджетирования по результатам можно отнести следующее:

- предоставление государством населения только тех общественных благ и услуг, в которых общество реально нуждается. Бюджетирование по результатам дает финансирование тех общественных благ и услуг, количество, качество, стоимость, время и место оказания которых в большей степени отвечает нуждам общества и характеризуется высшими показателями социальной результативности при указанных ресурсных рамках;

- переход на бюджетирование по результатам дает возможность критически продумать имеющиеся направления затрат средств и отказаться от большинства видов затрат, осуществляемых по ходу, без необходимого социального и экономического объяснения необратимости этих затрат;

- подбор решений проходит вместе с приоритетами среднесрочной политики, а не мгновенных результатов.

- ужесточается ответственность государственных органов за ожидаемый результат, под которым имеется в виду не только оказание определенного количества услуг или оказание конкретного объема работ, но и направленность на получение конкретных качественных показателей;

- увеличивается законность решений о государственных затратах. Заметно увеличивается информационная основа используемых правительством бюджетных решений. Так, информация о степени влияния различных уровней финансирования бюджетных программ на социальную и экономическую эффективность и результативность государственных расходов, дает возможность сбалансировано уменьшать затраты, не уменьшая программы.

Вместе с тем, проводимая в настоящее время в Казахстане бюджетная политика не в полной мере отвечает требованиям результативного использования бюджетных 
средств. Планирование бюджетных затрат в общем базируется на показателях нормативных издержек и не учитывает эффективности финансируемых работ. У этого метода имеется ряд недостатков.

Во-первых, при нормативном бюджетировании появляется нерациональные стимулы к увеличению издержек, потому что, при экономии средств в текущем году организация обязательно урежет бюджетные расходы на предшествующий год. Планирование бюджета производиться «от достигнутого». Базой для расчета затрат по статьям являются финансовые и натуральные нормативы, которые в целом создаются в увязке со штатной численностью, количеством занимаемых органом помещений и других параметров. Все это приводит к тому, что государственные органы стараются увеличить свои штаты и получить дополнительное финансирование.

Во-вторых, при этом планировании нет стимулов эффективной деятельности, потому как эффективность не учитывается напрямую при распределении бюджета. Отсутствие увязки объемов предоставляемых ассигнований объему и сложности осуществляемых функций, а также невозможность конкретной дифференциации оплаты труда, ограниченность оперативного распоряжения затратами на содержание дробными статьями бюджетных росписей, ведет к отходу целей деятельности от их ресурсного обеспечения. В итоге одни функции финансируются излишне, а другие нет.

В-третьих, руководство государственных органов ограничено в свободе использования предоставленных средств, что не дает осуществить затраты в соответствии с задачами деятельности, объемами и специальными требованиями, предъявляемыми характером исполняемых функций. Главными параметрами контроля являются статьи затрат, а критериями - целевое, своевременное и полное применение выделенных средств. Эти механизмы затрудняют рациональное использование бюджетных средств и не дают организациям быстро реагировать на изменения внешней среды, изменять свою деятельность в зависимости от изменяющихся нужд в государственных услугах, применять новые способы оптимизации деятельности.

B-четвертых, планирование бюджета на базе параметров имеющейся структуры органа, предоставление средств в строжайшем соответствии с принятой сметой, управление использованными ресурсами, а не за итогами деятельности приводят к слишком централизации бюджетных и финансовых полномочий. Появляется большой, непроизводительный и неэкономный по времени и ресурсам поток финансовых согласований, контроля и отчетности, заменяющий не в полной мере основную деятельность.

Все это оказывает влияние на качество предоставляемых конкретными органами государственных услуг.

Повышение эффективности проводимой в настоящее время бюджетной политики затрудняется также большим количеством программ, реализация которых закреплена за различными государственными органами. Имеет место дублирование направлений финансирования и инструментов реализации программ. Текущая 
ситуация показывает все еще слабую взаимосвязь стратегического и бюджетного планирования. Выделение бюджетных средств осуществляется под смету, а не под конечный результат. В связи с незавершенностью и продолжением структурных реформ достаточно сложно обеспечить в Казахстане, как стране с развивающейся экономикой, стабильность среднесрочного бюджетного планирования. Нельзя не сказать о существующей системе целевых трансфертов, которая, к сожаленью, на современном этапе не в полной мере выполняет выравнивающую функцию, что соответственно влечет за собой определенные дисбалансы в бюджетной системе. В 2012 году трансферты регионам составили в среднем 61,7\% в общем объеме доходов местных бюджетов. Как показывает анализ, объем финансовой помощи регионам из республиканского бюджета из года в год увеличивается, при этом анализ исполнения целевых трансфертов, выделенных на реализацию местных инвестиционных проектов показывает неэффективное и не своевременное использование средств трансфертов местными исполнительными органами. Усложненная система планирования расходов бюджета, множественность целевых трансфертов, неразработанность инструментов передачи финансовых ресурсов администраторам создает значительные проблемы в организации межбюджетных отношений. В результате снижается самостоятельность, ответственность и эффективность работы местных органов в решении задач социально-экономического развития регионов.

Все вышеперечисленные проблемы предопределяют необходимость реформирования всего бюджетного процесса, изменения подходов к формированию и реализации бюджетной политики Казахстана.

\section{Механизмы совершенствования бюджетной политики государства}

Меры по повышению эффективности государственных расходов актуальны практически во всех странах, не зависимо от того, исполняется ли их государственный бюджет с дефицитом или профицитом. На необходимость оптимального расходования средств в условиях предельной ограниченности ресурсов указывалось в послании Президента, что эта задача не утратила своей актуальности, хотя страна в этот период имела уже бездефицитный бюджет. В Республике Казахстан была подготовлена Концепция бюджетной политики [14], где подчеркивают важность повышения эффективности государственных расходов и активно ищет пути такого повышения. Концепция предусматривает ключевые направления оптимизации государственных расходов, повышения их социальной и экономической эффективности. Многие положения Концепции уже реализуются на практике, что свидетельствует об актуальности проблемы и правильности выбранного пути. В частности, проделана большая работа по инвентаризации обязательств бюджета, оценке эффективности государственных расходов в важнейших областях государственной политики (здравоохранение, образование и др.), по созданию механизма, препятствующего принятию законов без учета их последствий для бюджетной системы. 
Важным направлением совершенствования бюджетной политики является обеспечение взаимосвязи стратегического, экономического и бюджетного планирования. В этой связи необходимо провести ревизию и оптимизацию всех документов системы государственного планирования, для чего предлагается разделить и систематизировать их в рамках трех основных уровней документов системы государственного планирования:

Первый уровень - это документы, определяющие долгосрочное видение развития страны с ключевыми приоритетами, ориентирами и национальными показателями (в Казахстане - это Стратегия 2050, Стратегические планы развития на 10-летний период, Прогнозная схема территориально-пространственного развития страны).

Второй уровень - это документы с показателями развития отраслей и регионов, определяющие пути достижения документов I уровня, на основе их декомпозиции. К таким документам можно отнести государственные программы, Прогноз социально-экономического развития, отраслевые программы, Программы развития территорий.

Третий уровень - документ, определяющий стратегию развития сферы или отрасли по достижению показателей документов 1 и 2 уровня. Таковыми документами являются стратегические планы государственных органов.

Еще одним важным приоритетов совершенствования бюджетной политики является изменение подходов к формированию бюджетных программ. Предполагается, что бюджетные программы будут финансироваться по функциональным направлениям деятельности государственного органа. Так, к примеру, бюджетные программы Министерства образования и науки Республики Казахстан должны финансироваться 7 основным функциональным направлений деятельности, такие как:

- дошкольное воспитание и обучение

- начальное, среднее образование

- техническое и профессиональное образование

- высшее и послевузовское образование

- наука, научно-техническая деятельность

- молодежная политика

- защита и охрана прав детей

- аттестация, переподготовка, повышение квалификации педагогических кадров и т.д.

Введение системы мониторинга и оценки бюджетных программ влечет за собой обязательное изменение структуры годового отчета об исполнении бюджета, представляемого в представительные органы. Так, аналитический отчет об исполнении бюджета должен содержать в себе информацию о результатах, достигнутых по итогам исполнения бюджетных программ, направленных на реализацию приоритетных направлений социально-экономического развития. 
Обязательным условием является выведение службы внутреннего контроля государственных органов из системы государственного финансового контроля с преобразованием в службу внутреннего аудита центральных и местных исполнительных государственных органов. Указанные подразделения должны быть составной частью процесса управления организацией и заниматься проведением проверок внутренней практики и процедур государственного органадля обеспечения достижения целей организации.

В Республике Казахстан одним из главных принципов при исполнении бюджета, является принцип транспарентности, в соответствии с которым уполномоченный орган публикует и размещает на сайте данные по бюджету, что обеспечивает доступ к информации на всех стадиях бюджетного процесса.

С сентября 2012 года запущен новый сайт Министерства финансов, который отвечает новым требованиям оценки эффективности деятельности министерства в сети Интернет. Это дает возможность для проведения форумов с обсуждением актуальных вопросов, в том числе по исполнению бюджета и бюджетных приоритетов социального направления.

Республика Казахстан по индексу «открытости бюджета» оценивается с 2006 года и с каждым годом повышает свой рейтинг (2008 год - 35 баллов, 2010 год - 38 баллов, 2012 год -48 баллов).

В 2012 году Казахстан набрал 48 баллов из 100 возможных, что превышает среднюю оценку в 43 балла по 100 исследуемым странам.

Основным достижением в открытости бюджета является формирование Гражданского бюджета, который предназначен для ознакомления граждан с основными направлениями государственного бюджета с использованием адаптированных форматов и доступного языка, при этом любому пользователю становится понятно, каким образом Правительство Республики Казахстан осуществляет аккумулирование, распределение и использование общественных ресурсов.

\section{Заключение}

Таким образом, проведенный анализ показал, для повышения эффективности бюджетной политики в Республике Казахстан необходимо:

1. Обеспечить взаимоувязку стратегического, экономического и бюджетного планирования;

2. перейти к качественно новым подходам к формированию бюджетных программ, исходя из функциональной направленности деятельности государственных органов;

3. пересмотреть методологические подходы к проведению оценки эффективности и анализа государственных расходов с исключением дублирования контрольно-надзорных функции уполномоченных органов; 
4. активно вовлекать местные органы управления в перераспределении национального дохода и макроэкономической стабилизации, что может привести к более тесному бюджетному сотрудничеству региональных и центральных государственных структур;

5. повышать роль местных органов управления в системе распределения налоговых доходов, в том числе и общегосударственных;

6. проводить активную политику горизонтального бюджетного выравнивания, повышения ответственности центра за состояние местных бюджетов, уровня социально-экономического развития территорий.

\section{Литература}

1. Послание Президента Республики Казахстан народу Казахстана от 14 декабря 2012 г. (2012) Стратегия «Казахстан - 2050» Новый политический курс состоявшегося государства». www.akorda.kz/

2. Постановление Правительства Республики Казахстан от 26 декабря 2007 года (2007) N 1297 «О Концепции по внедрению системы государственного планирования, ориентированного на результаты». www.akorda.kz/

3. Бюджетный кодекс Республики Казахстан: Закон Республики Казахстан от 4 декабря 2008 года № 95-IVc изменениями по состоянию на 23.11.2012. БД «Юрист»: http:// www. zakon.kz. (2008) - 4 декабря.

4. Терни Питер. (2006) Разумный учет: как получить истинную картину затрат с помощью системы АВС/Питер Терни: Пер. с англ. Татьяны Родиной, к.э.н. Ольги Поповой, Никиты Пирогова. М.: ИД «Секрет фирмы», 2006. 384 с.

5. Блондал Й., Кристенсен Й. (2002) Бюджетирование в Нидерландах, OECD Journal on Budgeting, том 1, №3, 2002 г.

6. Kristensenm J. K. (2002) "Overview of Results Focused Management and Budgeting in OECD Member Countries," OECD, Paris, 2002.

7. Чертан К. (2003) Примеры передового опыта по разработке планов Главных распорядителей бюджетных средств на основе принципов бюджетирования, ориентированного на результаты». М.: ЭКОРИС-НЭИ. 2003. 46 с.

8. Gordon G. (2003) Strategic planning for local government. Washington, DC: ICMA. 1993.

9. Юнгман, И. (2005) Бюджетный процесс как инструмент эффективного управления Текст. / И. Юнгман; пер. со швед. Г. Иванов, В. Мерзляков - Intellect, tryckindustri, 2005. 255 с.

10. Силуанов А. Г. (2011) Межбюджетные отношения в условиях развития федерализма в России. М.: Издательство «Дело» РАНХиГС, 2011. 296 с.

11. Васильева М. В.(2011) Совершенствование управления экономикой регионов на основе формирования эффективной системы государственного и муниципального финансовобюджетного контроля: методология, концепция, перспективы: монография /М.В. Васильева. - Волгоград: Изд. Волгоградского государственного университета, 2011.

12. Зейнельгабдин А. Б. (2008). Финансовая система Казахстана: становление и развитие: монография. Астана: Изд. КазУЭФиМТ, 226 с. 
13. Кучукова Н. К. (2002). Законодательные основы реформирования бюджетной системы Республики Казахстан. Финансы. No 7. С. 58-62.

14. Постановление Правительства Республики Казахстан от 31 мая 2013 года (2013) № 561 О проекте Указа Президента Республики Казахстан «Об утверждении Концепции новой бюджетной политики Республики Казахстан».

\section{Margarita Kadyrova}

\section{Kazachstano Respublikos biudžeto politikos tobulinimo prioritetai*}

\section{Anotacija}

Straipsnyje analizuojami šiuolaikiniai Kazachstano Respublikos biudžeto politikos formavimo ir igyvendinimo aspektai, biudžeto planavimo mechanizmai ir metodai bei išteklių panaudojimo tobulinimo perspektyvos. Ypatingas dėmesys kreipiamas ị biudžetinio sektoriaus problemas, kurių aktualumas ir kompleksiškumas lemia tolesnių mokslinių tyrimų poreikį.

\section{Margarita Kadyrova}

\section{Priorities of Improvement of the Budgetary Policy in the Republic of Kazakhstan}

\section{Abstract}

In the following article, current issues of formation and implementation of budgetary policy of the Republic of Kazakhstan are considered, mechanisms of budget planning methods and budgetary resources utilization improvements are analyzed. A special emphasis is placed on the existing problems in the budgetary sector, which determines the need for further research in this area.

Margarita Kadyrova - Viešojo administravimo akademijos prie Kazachstano Respublikos Prezidento docentè, ekonomikos mokslų daktarè, Astana, Kazachstanas.

E. paštas: margarita-k06@mail.ru

Margarita Kadyrova, PhD in Economics, Academy of Public Administration under the President of the Republic of Kazakhstan, Associate Professor.

E-mail: margarita-k06@mail.ru

Straipsnis įteiktas redakcijai 2013 m. spalio 7 d.; recenzuotas; parengtas spaudai 2013 m. spalio mèn.

Pranešimas šio straipsnio tema buvo pateiktas elektroninėje konferencijoje „Viešasis administravimas centrinejje Europoje: tradicijos paieškos“, organizuotoje Mykolo Romerio universiteto Viešojo administravimo instituto kartu su Akademine vadybos ir administravimo asociacija (AVADA) $2013 \mathrm{~m}$. lapkričio 6-7 dienomis. 